ESCUELA DE MEDICINA DE MEXICO

\section{LA NIGUA}

(RHINCOPRION PENETRANS OKEN)

TESIS INAUGURAL

DE

DONACIANO CANO Y ALCACIO 


\title{
APUNTES DE ZOOLOGÍA MÉdiCA.
}

\section{LA NIGUA}

\section{(RHYNCOPRION PENETRANS OKEN)}

\section{TESIS INAUGURAL}

\author{
DE \\ DONACIANO CANO Y ALCACIO \\ Fimaceutico.

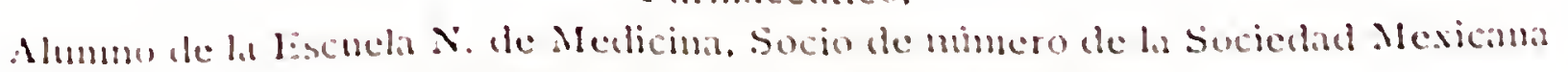 \\ de Hestoria Natural, Preparalor imerino \\ eul la clase de Historia Natural de la Escuela $x$. de Agriculura. \\ Miembro \\ de la Sociedad libiobrica y de Beneticencia.
}

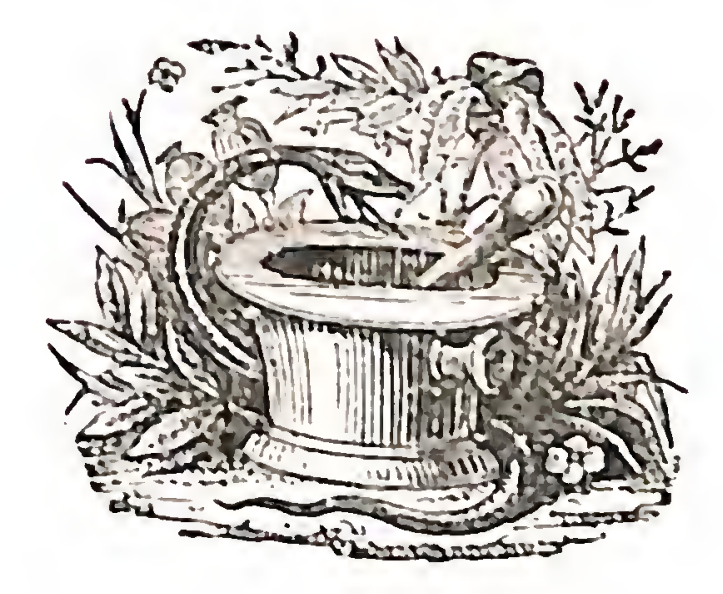

\section{MíxICO}

IMPREN'A DE FRANCISCO DIAZ DE LEON

Calle de Lerdo sọ.

1885 


\section{AL Sr. Dr. ALFREDO DUGÈS}

EL DR. FRANCISCO MONTESDEOCA

\section{AL ILUST'RE CUERPO DE PROFESORES}

DE LA ESCUELA NACIONAL DE MEDICINA 


\section{E S C R I P C I Ó N.}

\section{Sinonimia vulgax.}

Nignar (México).-Pigne, pique, pico (Perú).-Bicho, Bi(ho dos pes, tungi, pigne, tom, ton, sico, jatecuba, migor, ut, tungay (Brasil).-Chique (Francia).

\section{Sinonimia cientifica.}

Rhyncoprion penetrans, Olien.

Pulex penetrins, Lineo.

Dermatophylus penetrans, Guerin.-Meneville.

Sareopsylla penetrans, Westwood.

\section{HISTÓRICO.}

La nigua es un parásito perteneciente á la clase de los insectos, entre los cuales hay un orden denominado por Geer Chupadores, correspondiente á los Sifonápteros de Latreille y á los Afanípteros de Kirby.

Por el hecho de no tener alas se les había colocado en un grupo especial que comprendía las chinches, los piojos, las pulgas, etc., y los llamaban 
Apteres: pero algunos entomologistas, en razón de la estructura de la boca de estos animales, los colocan en el orden de Hemípteros; otros, por las metamórfosis los consideran como Dípteros, y algumos, como el sabio naturalista Antonio Dugès, los tenían por Himenópteros. El Sr. Dr. Alfredo Dugès, en la nueva edición de su zoología, que estí acabando de imprimir el Ministerio de Fomento, dice al hablar de la clasificación de los insectos: "En el cuadro sinóptico que damos aquí no ponemos por separado los insectos (Chupadores ó Sifonápteros, Anopluros ó Parásitos, 'Tisanuros), porque hay lugar de colocar cada uno de estos pretendidos órdenes en alguno de los otros por más que difieran por ciertas particularidades," y coloca la nigua entre los Dipteros.

Kirby forma un orden que denomina Afanipteros, completamente separado de los otros órdenes arriba mencionados: lo divide en dos tribus, los Pulicídeos (la pulga p. e.) y los Platipsídeos.

La nigua pertenece á la primera de estas tribus cuyos caracteres, son: ${ }^{1}$ Rostro compuesto de dos maxilas bajo la forma de piezas foliáceas, llevando cada una en la base un palpo maxilar cuadri-articulado: dos mandíbulas espadiformes festonadas en sus dos bordes, mal consideradas como los agentes principales de las picaduras, pues no son rígi-

1 Véase Magnin._Les parasites et les maladies parasitaires. 
dos y se pliegan fícilmente: una lengüieta estiliforme, rígida, tan larga como las mandíbulas, siendo ésta el principal órgano perforador: una vaina articulada, en forma de canaladura, sostiene la lengiieta y las láminas mandibulares foliáceas únicamente en el primer tercio de su longitud; esta pieza no es otra cosa que el labio, pues está terminado por dos palpos labiales cuadri ó bi-articulados: antenas poco visibles, cortas, de diez artículos, el primero piramidal truncado, los otros agrupados para formar un botón olivar, el todo colocado en una ranura dirigida hacia atrás y hacia abajo; en los machos de ciertas especies son más largas y pueden enderezarse: cabeza de un solo artículo elipsiforme, comprimido, parece algunas veces dividido en dos; borde inferior desnudo ó dentado: tórax de tres artículos separados, cada uno lleva un par de patas: patas largas, propias para el salto, principalmente el tercer par, compuestas de una anca grande, un muslo y una pierna voluminosos, separados de la anca por un pequeño trocínter; un tarso de cinco artículos; el primero es más largo y el quinto bi-ungulado: abdomen de diez anillos entrecruzados á los lados; el penúltimo tiene ordinariamente, en la parte superior, sobre la línea media, un escudete excavado, reniforme, llamado pigidium, sobre el cual están dibujados aereolos, dispuestos irregularmente, rodeados de un círculo de 
pequeñas perlas, en el centro de las cuales está implantada una pequeña cerda espinosa. Todas las piezas del abdomen y del tórax están imbricadas, y el cuerpo y las patas tienen pelos espiniformes. En el borde de la cabeza, en los anillos del abdomen y del tórax, por la parte superior, las cerdas, en algunas especies, están reemplazadas por gruesas y anchas espinas negras, cuyo conjunto simula un peine. El aparato respiratorio está formado por tráqueas que comunican con el exterior por los dos pares de estigmas que hay en el tórax y un par sobre cada uno de los ocho primeros anillos del abdomen. ${ }^{1}$

El macho tiene dos grandes estiletes copuladores metidos en el abdomen. La reproducción es ovípara. De los huevos muy voluminosos salen las larvas ápodas, de rostro organizado como el de las típulas, y la ninfa se cubre de un capullo sedoso.

En un género particular, que forma una sección aparte, la hembra procrea un número considerable de huevos, que acumulándose en el abdomen le centuplican su volumen.

Megnin divide la tribu de Pulicídeos en tres géneros: Rhyncoprion, Pulex y Mycetopsilla.

La nigua pertenece al género Rhyncoprion, cuyos caracteres son ( véanse las figuras $3 ?$ y 4 ? ), ade-

1 Cuando hagamos la descripción de la nigua hembra, observada al microscopio, se verá que el numero de estigmas se reduce a dos, pues los otros desaparecen como incitiles, y en virtud de la modificación tan profunda que sufre el abdomen del insecto en su vida sub ó intra-epi-
dermica. 
más de lojs de ìa tribu que se ven bien en las figuras citadás: el abdomen sólo tiene bien marcados nueve artículos con algunas estrías cortas, no tiene pigidium sobre el penúltimo anillo, patas semejantes í las del género Pulex (yo añadiría que están cubiertas desde la anca hasta la tibia, de una infinidad de puntas cónicas cortas, hasta cierto punto gruesas, muy bien marcadas y visibles con un pequeño aumento), con las cuales salta, pero menos que el Plilex irritans (Pulga del hombre).

Hasta ahora no se ha descrito más que una sola especie: el Rhyncoprion penetrans, de Oken.

Mi maestro, el Sr. Dr. Alfiedo Dugès, ha examinado varios ejemplares que le remití el año de 83, recogidos por mí en la Hacienda de Santa Catarina, situada entre Santa María del Rio y Rio Verde, Estado de San Luis Potosí, muy al principio de la Huasteca Potosina. Sus repetidos estudios le han hecho creer que se trataba de ma especie nueva aun no descrita. Remitió á Megnin ejemplares y dibujos, quizá los primeros bien sacados, manifestándole su opinión; pero este señor contesta diciendo que es el Rhyncoprion penetrans, de Oken.

El macho es más pequeño que la pulga ordinaria, tanto que quien no tiene costumbre de verlas, difícilmente las encuentra. El macho y la hembra no fecundada tienen la misma talla $\left(0,{ }^{\mathrm{m}} \cdot 001^{\mathrm{mm}}\right)$, con el cuerpo de forma ovovada, color pardo, rojizo, con 
una mancha blanca sobre el dorso, los tegumentos son tan resistentes que difícilmente se desgarran: las patas son del mismo color que el cuerpo, con las articulaciones blanquizcas. Los ejemplares que yo he estudiado me han presentado todas las patas, desde la anca hasta la tibia, con una multitud de puntas cónicas, agudas, cortas y bastante gruesas, visibles con un pequeño aumento (v. fig. 3?). Seguramente esta particularidad no la tenían los ejemplares que el Sr. Dugès examinó, pues la figura $4^{\mathrm{a}}$ sacada por él no contiene ese detalle que quizá sea específico; por eso he querido publicar estas dos figuras que parecen diferir algo tal vez por pertenecer á dos especies diferentes, salvo la muy respetable opinión de Megnin.

La hembra fecundada necesita una gran cantidad de alimento para llevar á buen término su progenitura, que se compone de una gran cantidad de huevos, los cuales se desarrollan por completo en el interior del abdomen. Por eso se introduce en la piel del hombre ó de los animales para chupar la sangre en tanta cantidad como la necesita; así aumenta considerablemente de volumen y con tal rapidez, que á las venticuatro horas ya se nota á la simple vista, adquiriendo en poco tiempo el tamaño de un chícharo.

Extraído el animal tiene el aspecto de un quiste de $0^{\mathrm{m}}, 005^{\mathrm{mm}}$ de diámetro, de forma esférica, un poco 
comprimida hacia los puntos correspondientes á la cabeza y ano, es de un color blanco brillante, dejando ver en las partes comprimidas dos puntos negros: el más pequeño pertenece á la cabeza y el más grande al último anillo del abdomen.

Para completar lo relativo á la anatomía de la nigua hembra, diré lo que mi amigo el Dr. Felipe Larios y yo hemos encontrado en nuestros exámenes al microscopio, hechos sobre cortes antero-posteriores del abdomen de la nigua en pleno desarrollo: uno de esos cortes está representado en la figura 2: dibujada con toda exactitud por Larios. Se ve en esta figura la envoltura (a) formada por los tegumentos externos del abdomen del insecto modificados, pues es una membrana de tres capas uniformes, sin estructura y sin señal ninguna de los artículos $o ́$ anillos que en el estado errante del insecto formaban el abdomen; lo único que no se modifica y que conserva los caracteres de segmentos quitinosos, son las piezas que forman la cabeza, el tórax, las patas y el último anillo del abdomen: este anillo lleva las piezas cómeas del ano.

En el interior de esta bolsa abdominal se ven una infinidad de huevos ( $b b b$ ) diseminados, sin orden y enteramente libres. Estos huevos, como se verá en los números desde el 1 hasta el 8 , observados con 300 diámetros (mayor aumento), se presentan en sus diferentes estados de desarrollo; pues 
los más jóvenes tienen el aspecto de celdillas colocadas en serie (1) y comprimidas por las caras que se tocan, disposición debida á la forma del tubo ovariano en donde nacen: después se aislan unos de otros afectando la forma esférica (2). En este estado se ven como en el anterior, formados de una membrana simple, un contenido granuloso (vitelo) y un enorme núcleo (vesiculagerminativa); después la membrana de envoltura adquiere un doble contorno (3) sin cambiar sensiblemente las dimensiones del huevo: cuando éste ha adquirido mayores proporciones, el vitelo comienza á segmentarse (4) y á formar una capa de celdillas debajo de la membrana de envoltura, capa que toma el aspecto de una cubierta epitelial, quedando el resto del vitelo granuloso con su núcleo muy grande: después (5) continúa la segmentación del vitelo, apareciendo hacia la parte más superficial de él, pequeñas esferitas brillantes, claras y trasparentes con el aspecto de gotas de grasa, pero se coloran con el carmín: las celdillas de la periferia crecen y su núcleo se hace aparente, el vitelo continúa su segmentación, pero aun se nota una parte granulosa envolviendo la vesícula germinativa rechazada hacia uno de los polos del huevo que se ha alargado mucho: el vitelo que aun estaba granuloso desaparece (6), quedando el núcleo rodeado por todas partes por las bolas de segmentación. La membrana de en- 
voltura (7), que desde que empezó la segmentación del vitelo había perdido su doble contorno, vuelve á adquirirlo muy aparente, las celdillas periféricas que la tapizan interiormente pierden su núcleo y se atrofian, y la vesícula germinativa desaparece, quedando por último el huevo reducido á una membrana de envoltura, con doble contorno, anista, llena por las bolas de segmentación que representan el primer rudimento del blastodermo. Hay que notar aquí que la aparición de las celdillas que cubren la cara interna de la membrana de envoltura del huero, coincide con la desaparición del doble contorno de esta membrana; y la reaparición del doble contorno, coincide con la atrofia de dichas celdillas. i Será una simple coincidencia, ó habrí entre estos dos fenómenos relación de efectos ó causa?

Hasta este estado hemos observado los huevos. Lamentamos no haber podido observar algo del desarrollo del embrión. Tampoco hemos podido ver nada que se parezca á una larva, para comprobar lo que el Sr. Andrade dice pudo ver una sola vez ${ }^{1}$ en las niguas extraidas de los piés de la enfermita citada en su memoria leida en la Academia de Medicina el año de 1883.

Siguiendo el examen de nuestra figura 2 , vemos en ( $\left.\begin{array}{ccc}c & c\end{array}\right)$ el aparato digestivo, que en su primera porción es muy grueso, cubierto interiormente en 
toda su extensión por una gran cantidad de vellosidades (v. no 13). A medida que se aproxima á la extremidad anal, va disminuyendo de cliámetro, y después de muchas vueltas termina en el ano, llevando un esfinter de músculos estriados (v. 11:11). En fin, se encuentra una gran cantidad de tubos traqueales, trasparentes, de diámetros desiguales, sin estructura aparente en sus porciones más delgadas: se colocan en todos los intersticios que dejan las vísceras, dando finísimas ramificaciones: el tronco de este aparato respiratorio es doble $\mathrm{y}$ toma su origen á los lados del ano, donde se ven dos tráqueas bastante gruesas, con la membrana que las tapiza interiormente muy rugosa trasversalmente y cubierta de puntitos salientes, como espinitas, y ligeramente inclinados hacia el exterior (v. $\left.n^{\circ} 10\right)$. El principio de esta tráquea está precedido de una dilatación ampular (cúmara estigmática) cubierta en toda la extensión de su cara interna por abundantes y finísimos pero rígidos pelos, que dirigiéndose de adentro hacia fuera se entrecruzan en la línea media formando así un fino tamiz á través del cual se cuela el aire que penetra al aparato respiratorio: esta cámara comunica con el exterior por un pequeñísimo orificio, el estigma.

Se ven además abundantes músculos con estria-

1 Véase Gaceta Médica de México. Tomo XVIII, entrega 21. 
ción doble agrupados sobre todo en el extremo cefálico (d) y en el extremo abdominal (e); aquí rodean el ano y las tráqueas y se insertan en el último anillo quitinoso del abdomen, así como en las piezas córneas del ano.

La nigua escoge siempre, para llevar su vida parásita, al hombre, eligiendo de preferencia para alojarse el surco que forma la uña con la pulpa del dedo, ó mejor dicho todo el contorno de la uña: se fija igualmente en las patas de los perros, los cochinos, los gatos, los caballos, las mulas, los asnos, pero se puede decir que prefiere sobre todos al hombre y á los cochinos; por esta preferencia la persona que no estíl atacada de nigua, y am cuando lo esté, debe entrar con muchas precauciones á las zahurdas. Vive también en abundancia en los escombros, en la tierra suelta, en la hoja seca, y parece que le agrada mucho la hoja ó basura de la caña de azúcar.

Es muy común en toda la Tierra Caliente del Territorio Mexicano, y aun en algumos lugares templados; se encuentra también en las Américas Central y del Sur, y no sé si la hay en algunos lugares de los Estados Unidos; pero de todos modos se puede decir que la nigua es un insecto americano. 


\section{LESION ES.}

\section{Primer grado.}

El macho no produce perjuicio alguno; su destino se cumple cuando fecunda á la hembra y no necesita vivir más, mucho menos como parásito. La hembra fecundada perfora con la lanceta rígida (que en el estado de reposo está oculta por las mandíbulas) la epidermis y las primeras capas de la dermis; con sus poderosas patas se apoya para poder penetrar hasta quedar completamente sepultada, dejando fuera solamente la extremidad del abdomen, para expulsar hacia el exterior las materias fecales y recoger el aire que penetra por los dos estigmas situados á los lados del orificio anal: de esta manera quedan aseguradas la nutrición, la respiración y la desasimilación. Antes de veinticuatro horas de haber penetrado, se ve, en la piel blanca, un puntito negro ó rojizo; en la piel oscura, y sobre todo en la gente pobre que no usa zapatos, es difícil distinguirla: á las veinticuatro horas ya se nota una pequeña mancha blanca cubierta por la epidermis con un punto rojizo muy marcado en el centro; al derredor hay una aureola roja 
de dimensiones variables; esta mancha va aumentando con bastante rapidez, sin formar relieve hacia el exterior, y si lo forma es muy ligero, y ésto solamente cuando varios insectos se han colocado muy próximos unos á otros, de suerte que al crecer su abdomen llegan á comprimirse lateralmente. El aspecto de estas manchas, á primera vista, da la idea de una pústula de viruela; pero se distingue fácilmente porque el punto oscuro del centro no es ombilicado. Cuando ha llegado al máximum de su desarrollo, la bolsa abdominal ocupa todo el espesor de la dermis ó poco menos si es gruesa; cuando es delgada llega hasta el tejido celular subcutáneo; las uñas tienen, á veces, un color negruzco y están levantadas (Andrade).

Extraido el quiste abdominal de la nigua, ó sea la nigua en pleno desarrollo, queda en su lugar una cavidad muy profunda de paredes rojas lisas y tapizadas por una membrana finísima y de fondo sumamente vascularizado; con frecuencia hay entre el quiste y las paredes de la cavidad que lo contiene, un ligero derrame seroso ó sero-sanguinolento.

\section{Segundo grado.}

El segundo grado está caracterizado por la supuración consiguiente á la inflamación de los tejidos que rodean el quiste: el pus se extiende á 
grados diferentes, formando algunas veces grandes colecciones situadas debajo de la epidermis que se trasparenta dejando ver una mancha blanca algunas veces del tamaño de un peso; este pus ocasiona la caida de las uñas y suele destruir todo el espesor de la dermis, lo que produce ma ulceración de la piel más ó menos extensa y profunda, con paredes casi siempre irregulares.

\section{Tercer grado.}

La destrucción de los tejidos y la extensión del pus no se limitan á la piel; forma extensas colecciones, destruye los tejidos profundos tales como músculos, ligamentos, etc., produce la gangrena de algunas partes y causa la pérdida de una ó dos falanjes y aun de todo un dedo. Hay muchos pobres mutilados de esta manera, cuyas cicatrices son sumamente irregulares y de un aspecto desagradable: á los que quedan sin los dedos de los piés les llaman vulgarmente chapines.

Estas lesiones se encuentran más comunmente en los dedos de los piés; pero no es raro verles en la planta, dorso y talón del pié, en la pierna y en las manos: el Dr. Ignacio Pombo asegura que se han encontrado en el prepucio y en el glande. ${ }^{1}$

La lámina primera, tomada del natural por mi

1 Véase Anales de la Asociacion Larrey.-Tomo 2. n? 12. 
amigo y compañero Luis Alcántara, representa las lesiones de primero y segundo grado que llevaba uno de los enfermos que observé en el Hospital Militar: este enfermo vino con otros dos del Estado de Veracruz, el mes de Abril de este año.

\section{SÍNTOMAS.}

Las personas de piel fina sienten perfectamente cuando el insecto comienza á perforar la piel, por el ligero piquete, que produce una sensación parecida á la que hace experimentar el piquete de una pulga. Cuando la piel es gruesa y no tienen costumbre de usar calzado ó zapatos, no se aperciben del momento en que han sido atacados. Una vez introducido, se experimenta al principio una ligera comezón que aumenta al rascarse, siendo por lo mismo interminable: la operación de rascarse les es muy agradable á los enfermos y algunos se rascan por verdadero placer: este síntoma existe mientras la nigua vive, y está sostenido por el constante trabajo de perforación que verifica el insecto á medida que su desarrollo le obliga á profundizar más y más. Cuando se pasa la mano sobre una nigua viva, se experimenta un ligero dolor pungitivo $y$ 
hasta cierto punto profundo ; ésta es la causal de que los enfermos que llevan un gran número de niguas en los dedos, no pueden andar sino sobre los talones, lo que es sumamente difícil é incómodo, y cuando tienen atacada esta última región y la planta del pié, se ven obligados á hacer cama.

La comezón tan viva, acompañada algunas veces de ardor, y el dolor pungitivo causado por una ligera presión ó el simple paso de la mano, son el atributo obligado de las lesiones de primer grado sostenidas por el insecto vivo.

Cuando por una causa cualquiera se inflama la pared de la cavidad que contiene á la nigua, hay, además, el dolor consiguiente á este proceso, dolor que se hace más intenso á medida que el número de niguas y la extensión de los tejidos inflamados es mayor; á veces se hace insoportable. Algunos enfermos sufien tanto que pierden completamente el sueño y están tan inquietos y desesperados, que con frecuencia se ven obligados á pedir de por Dios que les saquen las niguas.

Una vez verificada la formación del pus y bien coleccionado éste, se puede sentir más ó menos clara, según la cantidad, la fluctuación característica: entonces el dolor puede disminuir ó casi desaparecer, y si se pasa la mano sobre la nigua ó se comprime, no se produce el "dolor de clavo" (expresión muy usada por los enfermos) causado cuan- 
do aun no hay supuración, pues el pus aisla á la nigua del contacto con los tejidos vivos.

La nigua puede secarse y entonces la epidermis que la cubrc se endurece y cae espontíneamente cuando se ha regenerado el tejido epidérmico. A veces los enfermos se entretienen en pegarse pequeños golpes con la uña sobre estas partes secas, y se ve salir á cada golpecillo un gran número de huevos perfectamente blancos; he recogido algunos crejendo que estarían secos, pero los he encontrado perfectamente frescos, $\mathrm{y}$ con su vitelo en completo cstado de segmentación.

Se dan casos en que las partes atacadas quedan completamente anestesiadas por más ó menos tiempo. En los climas calientes se dice que el tétanos complica con frecuencia esta enfermedad después de la extirpación de los quistes.

DURACIÓN Y TERMINACIÓN.

Los padecimientos causados por las niguas pueden prolongarse por mucho tiempo, dependiendo ésto, tanto de la indolencia como de la falta de precauciones; pero si se atiende á tiempo oportuno, en unos cuantos dias desaparece la enfermedad: por consiguiente el pronóstico, aunque siem- 
pre benigno, está sujeto á muchas variaciones, pues con frecuencia el fagedenismo, la gangrena y quizá el tétanos, cambian completamente la escena. Sin embargo, se puede decir que la curación es la terminación natural y que solamente algunas veces deja huellas indelebles.

\section{TRATAMIENTO.}

La profilaccia es bien conocida; basta la limpieza, un buen calzado, registrarse los piés con frecuencia al acostarse, y evitar el tránsito por los lugares tan conocidos donde habita el insecto: los pobres que no pueden proporcionarse un buen calzado y que tienen necesidad de frecuentar los puntos donde hay niguas, harán bien en ponerse antes en los piés aguarrás, que causará la muerte de los insectos que quieran atacar ó impedirá hasta que se adhieran: una ligera embrocación con aguarrás es suficiente.

En cuanto al tratamiento curativo, lo primero que debe hacerse es la extirpación de las niguas; esta operación la practican con bastante destreza las gentes del pueblo, y para hacérsela sólo se sirven de una aguja gruesa de punta embotada intencionalmente; comienzan por levantar la epidermis en los límites del punto oscuro, que como consta 
en otro lugar, ocupa el centro de la mancha blanca; una vez levantada en casi toda la extensión de la circunferencia que rodea la superficie visible del quiste, se enúclea éste introduciendo entre sus paredes y las de la cavidad que lo contienen, la punta roma de la aguja; en este momento se ve la utilidad de la aguja embotada, pues se puede manejar con confianza sin grande temor de romper el abdomen del animal, ni de herir las paredes de la cavidad que lo contiene: cuando está enucleado, con la misma aguja introducida hasta el fondo se procura llevar hacia afuera la cabeza del insecto; conseguido ésto todo el quiste queda fuera de la cavidad y únicamente adherido por un punto próximo á la extremidad abdominal; se rompe esta adherencia con tijeras, y si no es muy fuerte, basta una ligera tracción para desprenderlo. Algunas veces, después de enucleado el quiste, basta comprimir con el índice y el pulgar un pliegue de la piel cogido entre estos dos dedos, de manera que la nigua ocupe la parte más saliente del plieg’ue; esta pequeña maniobra basta muchas veces para expulsar la bolsa formada por el enorme abdomen de la nigua.

Casi siempre al principiar la operación se ve salir un líquido oscuro, lanzado con fuerza bajo la forma de finísima lluvia, como si fuera lanzado por: un pulverizador. Esta es una de las mejores pruc- 
bas de que el insecto está vivo, pues impresionado por la EXCITACTÓN que le causa la maniobra, se irrita y hace funcionar sus aparatos contráctiles para lanzar ese líquido que bien puede usarlo como arma de defensa; pero probablemente son materias fecales.

Como la única parte fuertemente adherida á los tegumentos es la extremidad del abdomen, es decir, la parte más superficial del quiste, la más accesible, es más sencillo, para extraerlo, cortar de un tijeretazo ó con el escalpelo, rebanando esta parte como se hace con los callos; después bastan las pinzas para sacar el resto lleno de huevos.

Se tiene mucho miedo de romper la bolsa, porque quedan en el interior de los tegumentos los huevos que se derraman y pueden ser la causa de subsecuentes extragos, pues nacen nuevos animales que seguirán minando la piel; pero este temor no tiene razón de ser, pues dado caso que las larvas pudiesen nacer ahí y fuesen carnívoras, las curaciones que deben hacerse tienen por objeto desinfectar las úlceras á la vez que matar los insectos.

Cuando hay colecciones purulentas se abren ampliamente para limpiar á satisfacción, se lava luego cuidadosamente con alguna solución antiséptica á la vez que insecticida: recomiendo para ésto una soluciór acuosa al milésimo de bicloruro de mercurio, que destruirá toda la semilla que puede que- 
dar en el interior de las úlceras; las curaciones subsecuentes se pueden hacer con fomentos de solución acuosa de ácido bórico al 30 por 100. Así fueron curados los enfermos que observé en el Hospital Militar, quedando enteramente buenos en poquísimos dias.

El popular modo de curar las úlceras después de extirpada la nigua poniendo tabaco molido 6 ceniza del mismo, no puede ser más inconveniente.

Las complicaciones como el fagedenismo y la gangrena, no necesito mencionarlas en esta parte; solamente diré de la gangrena, que no hay mejor. remedio para acabar con el mal olor, ni mejor manera de determinar la limitación de este mal, que el recomendado y muchas veces usado por el Sr. Montes de Oca: el yeso calcinado en polvo; basta poner la parte gangrenada (se entiende de la gangrena húmeda) en un saco con yeso, para que esta sustancia absorba todos los líquidos y trasforme en poco tiempo la gangrena húmeda en gangrena seca, consiguiéndose con ésto tres grandes ventajas : primera, la limitación de la gangrena; segunda, la desaparición del mal olor, y tercera, cesa la absorción de los líquidos sépticos y todas sus consecuencias.

Donaciano Cano y Alcacio.

México, 1885. 



\section{ZOOLOGIA MÉDICA}

La Nigua.

Hig. I"

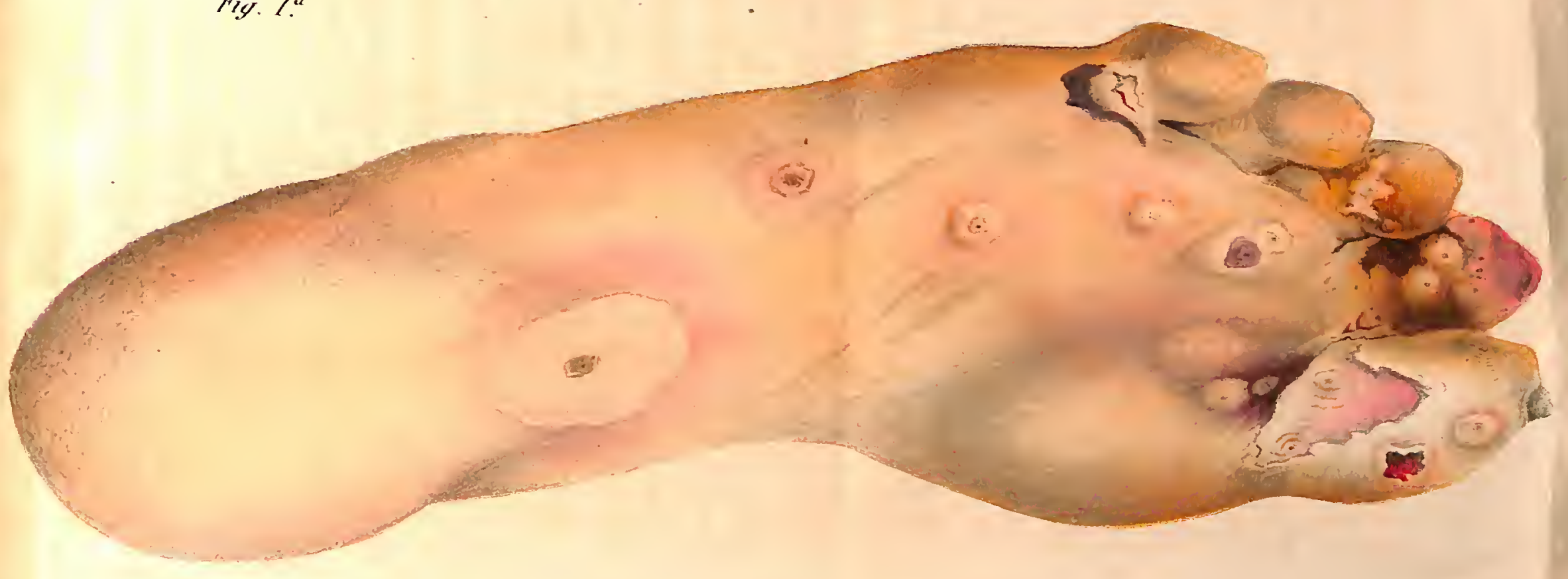

TESIS INAUGURAL de D. Cano y Alcacio. 


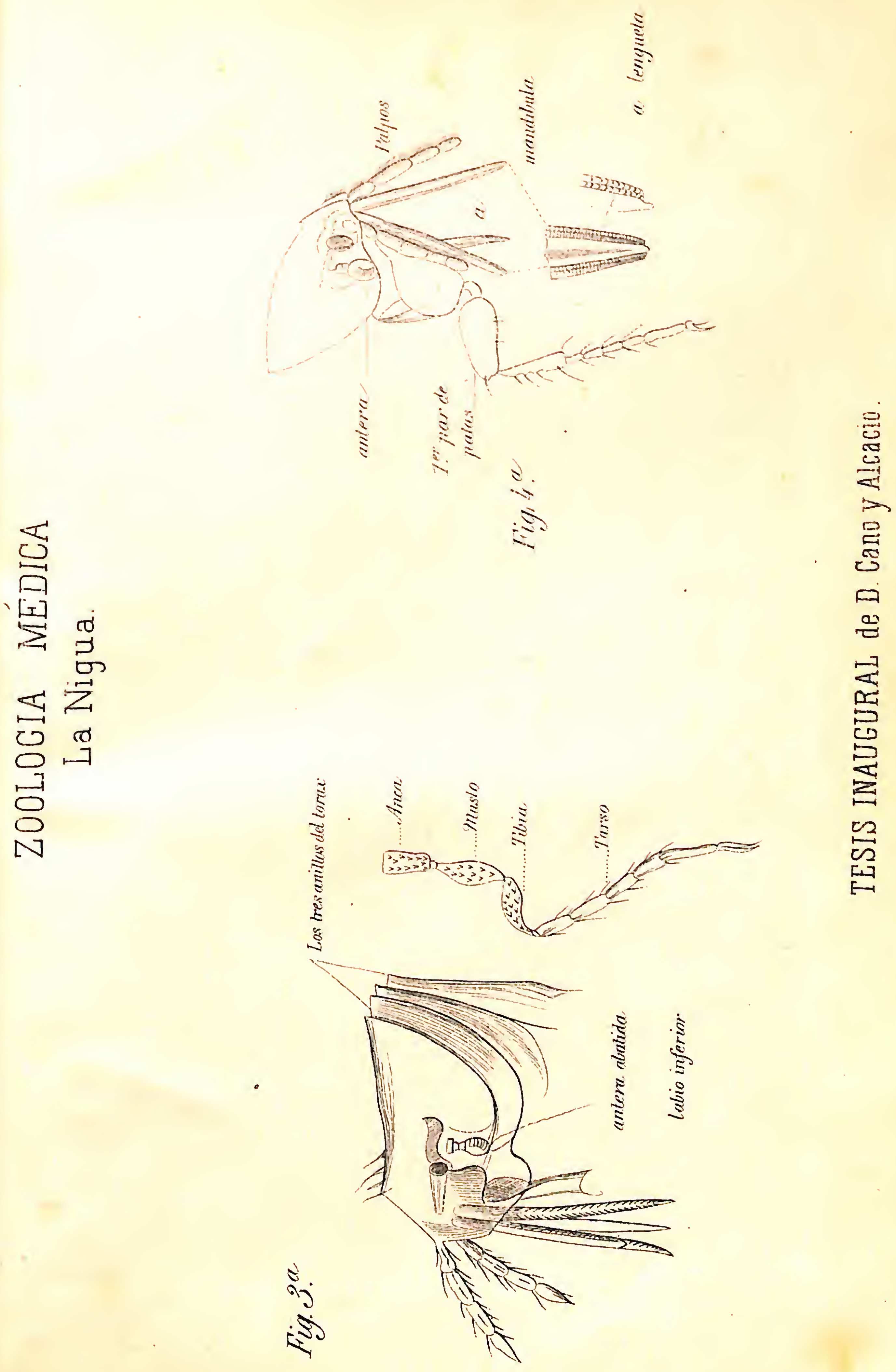
- 
.

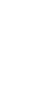





\section{UNAM}

\section{FECHA DE DEVOLUCIÓN}

El lector se obliga a devolver este libro antes

del vencimiento de préstamo señalado por el último sello

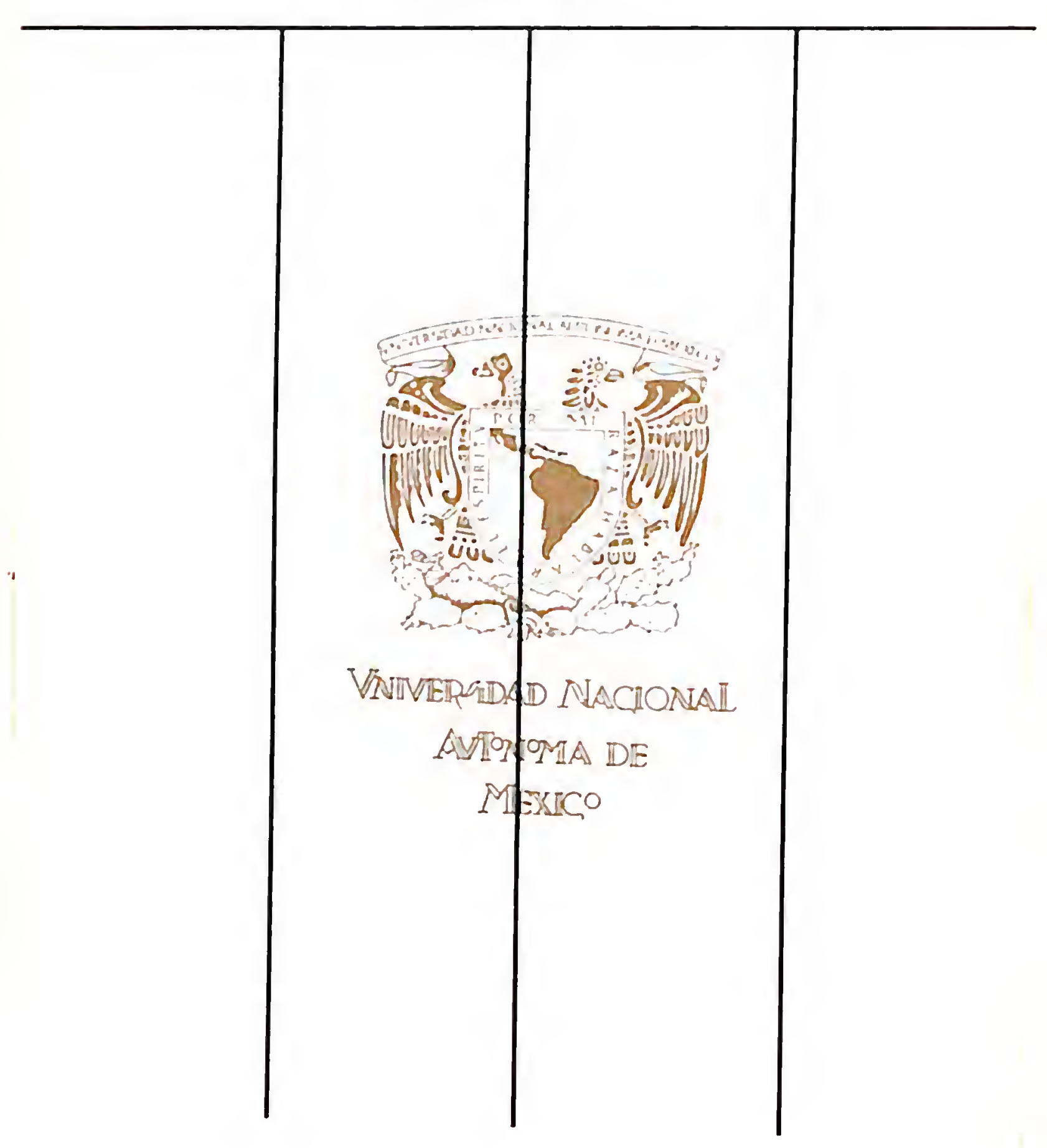


